\title{
The Pacific experience: supporting small island countries and territories to meet their 2012 International Health Regulations (2005) commitments
}

\author{
Adam Craig, ${ }^{a}$ Jacob Kool ${ }^{b}$ and Eric Nilles ${ }^{b}$ \\ Correspondence to Adam Craig (e-mail: adam@adamcraig.com.au).
}

Issue: By 15 June 2012, States Parties to the International Health Regulations (2005), or IHR (2005), were required to have established the core capacities required to implement Annex 1 of IHR (2005).

Context: The Pacific is home to 10 million people spread over 21 Pacific island countries and territories. Seven of those have populations of less than 25000 people; 14 of the 21 Pacific island countries and territories are States Parties to the IHR (2005).

Action: The World Health Organization Division of the South Pacific embarked on an initiative to support Pacific Island States Parties meet their 15 June 2012 IHR obligations. We adapted the 2012 IHR Monitoring Questionnaire (IHRMQ) to assist Pacific island countries and territories determine if they had met the capacities required to implement Annex 1 of the IHR (2005). If a Pacific island country or territory determined that it had not yet met the requirements, it could use the assessment outcome to develop a plan to address identified gaps.

Outcome: Direct support was provided to 19 of 21 (91\%) Pacific island countries and territories including 13 of 14 (93\%) States Parties. Twelve of 14 (86\%) fulfilled their requirements by 15 June 2012; those that had not yet met the requirements requested extensions and submitted plans describing how the IHR core capacities would be met.

Discussion: Adapting the 2012 IHRMQ for this purpose provided an efficient tool for assessing national capacity to implement Annex 1 of IHR (2005) and provided clear indication of what capacities required strengthening.

\section{ISSUE}

On 15 June 2012, five years after the International Health Regulations (2005), or IHR (2005), entered into force, the States Parties to IHR (2005) $)^{1}$ were required to have in place the core public health capacities required to implement Annex 1 of the IHR (2005), and, if it was found that the capacities needed were not yet in place, to request a two-year extension to allow more time to meet the requirements. ${ }^{2}$

As coordinating body for IHR (2005), the World Health Organization (WHO) monitors States Parties' progress towards fulfilment of the core capacity requirements. Central to this monitoring is the annual
IHR Monitoring Questionnaire (IHRMQ). ${ }^{3}$ The 2012 edition of IHRMQ was made available to States Parties in March 2012 to be completed and returned to WHO by 1 August 2012.

This paper describes how the WHO Division of the South Pacific used the 2012 IHRMQ to produce a tailored tool with which Pacific island countries and territories could determine fulfilment of their capacity to implement Annex 1 of IHR (2005) to meet their 15 June 2012 obligations. We discuss how we supported Pacific island countries and territories to apply the adapted tool and reflect on lessons learnt in the process. We hope that our experience in the Pacific will be informative for other similar contexts.

\footnotetext{
Public Health Consultant, Sydney, Australia.

Emerging Disease Surveillance and Response, Division of Pacific Support, World Health Organization, Suva, Fiji. Submitted: 9 October 2012; Accepted: 13 May 2013 Published: 10 July 2013 doi: 10.5365/wpsar.2012.3.4.007
} 
Figure 1. Map of the Pacific island countries and territories in the Western Pacific Region

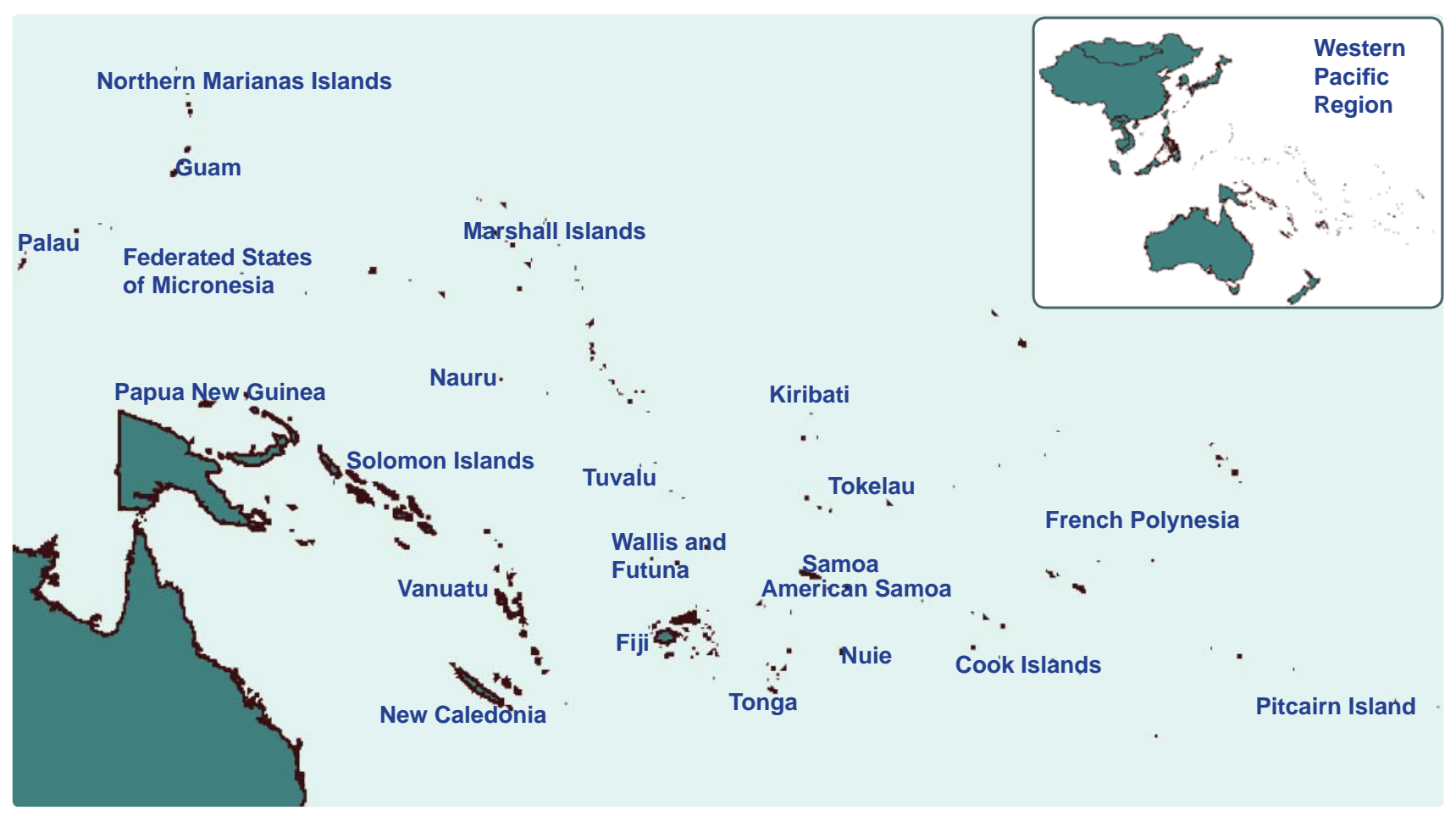

\section{CONTEXT}

The Pacific covers almost one third of the earth and is home to approximately 10 million people (excluding Australia and New Zealand which are developed countries that do not require technical assistance). ${ }^{4}$ Of these, 6.5 million reside in Papua New Guinea. The other 3.5 million Pacific Islanders are dispersed over many hundreds of islands and atolls that make up the other 20 Pacific island countries and territories (Figure 1). Seven Pacific island countries and territories have populations of less than 25000 , and three have populations less than 10 000; Tokelau has a population of just 1200 people. Fourteen Pacific island countries and territories are States Parties to IHR (2005), and seven are territories or administrative areas for which IHR (2005) responsibilities are delegated to their metropolitan country. The majority of the Pacific island countries and territories are considered to be of lowermiddle income. ${ }^{5}$

Small population size, geographic isolation and limited human and financial resources make independent achievement of many of the IHR (2005) core capacities extremely challenging for these island territories. Some of these challenges have been addressed by drawing on regionally based public health resources such as the Pacific Public Health Surveillance Network's (PPHSN) Laboratory Network ${ }^{6}$ and the WHO-led Pacific Syndromic Surveillance System, ${ }^{7,8}$ in addition to bilateral agreements with Pacific Rim countries such as New Zealand, Australia or the United States.

\section{ACTION}

\section{Assisting Pacific island countries and territories to meet their IHR (2005) capacity obligations}

In response to Pacific island countries and territories' requests for assistance, the WHO Division of Pacific Support (based in Suva, Fiji) embarked on a project to support States Parties meet their IHR (2005) notification obligations by 15 June 2012. WHO had committed this assistance through the Asia Pacific Strategy for Emerging Diseases (2010). ${ }^{9}$ Even though islands that are territories of other nations are not States Parties to IHR (2005), and therefore not required independently to report their progress directly to WHO (rather through their metropolitan country), we encouraged them to participate in the project for self-assessment purposes. Six of seven territories were enthusiastic to participate. 


\section{Adapting the 2012 IHRMQ for use as a tool to assess Pacific island countries and territories ability to implement Annex 1 of IHR (2005)}

The IHRMQ is an annual questionnaire developed for global use and sent to all IHR (2005) States Parties. It is an important source of information for countries to determine whether they have met the IHR (2005) core capacity requirements. It can be helpful to adapt this global tool for application to best meet the context of each region, country or territory. For this purpose, we analysed the questions in the 2012 IHRMQ to identify those that were most directly related and fundamental to the content of Annex 1 of IHR (2005) and were most pertinent to determining whether the core capacities had been established. ${ }^{1}$ To ensure consistency with the full 2012 IHRMQ we did not modify the wording of any of the questions; however, to make it more userfriendly and Pacific-oriented, we added explanatory/ interpretive notes beside relevant questions. Finally, we expanded the response options by adding: "Yes, drawing on international resources"; "Yes, drawing on national resources"; "No"; and "Not relevant". This allowed Pacific island countries and territories to more accurately reflect the situation in their jurisdictions, including where a Pacific island country or territory drew on regionally based networks or had bilateral agreements in place to achieve certain core capacities.

This tool was distributed to Pacific island countries and territories' National IHR Focal Points or public health focal points (for those that are areas/territories) in the week of 14 May 2012, approximately one month before the 15 June 2012 date for extension requests.

\section{Supporting Pacific island countries and territories assess their capacity achievement}

After we distributed the tool, Pacific island countries and territories were contacted and offered one-on-one telephone or e-mail assistance to explain and apply the tool. The form of assistance depended on the country or territory's needs, national decision-making processes and logistical factors such as stability of telephone lines or availability of relevant personnel. Usually, assistance was delivered as a series of telephone conferences focusing on specific aspects of IHRMQ that were of particular concern to a Pacific island country or territory.
On 31 May 2012, senior public health staff from 12 of 14 (86\%) States Parties and five of seven territories (71\%) met with WHO and Secretariat of the Pacific Community (SPC) staff as part of a Pacific region meeting. Important objectives of this meeting were to ensure the IHR (2005) assessment and reporting process was clear, to review the Pacific-wide public health networks and their roles in core capacity development and to provide additional one-on-one assistance to any Pacific island country or territory requesting further support.

\section{OUTCOME}

Direct support was provided to 19 of the 21 Pacific island countries and territories (91\%), including 13 of the 14 States Parties and six of the seven territories. Every effort was made to engage the two other Pacific island countries and territories.

Twelve of 14 States Parties completed their national assessments and determined their ability to implement Annex 1 of IHR (2005) by 15 June 2012 and reported the conclusion of their national assessment to $\mathrm{WHO}$ by the notification date. Six of the 14 determined that they had in place the capacities required to implement Annex 1 of IHR (2005) and did not request an extension. The other eight determined that they had not yet met the requirements and requested a two-year extension. As required, all States Parties requesting an extension submitted an implementation plan for how they would meet the IHR (2005) core capacity requirements within the extension period.

\section{DISCUSSION}

In the last two decades, WHO, SPC and the Pacific island countries and territories have worked closely to establish and sustain PPHSN (a voluntary network of Pacific island countries and territories' public health authorities, WHO, SPC and other regional public health entities) and Pacific-wide networks and services that provide important capacity support such as early warning for outbreaks, ${ }^{7,8}$ laboratory testing or outbreak response. Through the support of PPHSN, many of IHR (2005) core capacities are available to Pacific island countries and territories, some of which could never be achieved by smaller individual Pacific island countries and territories. For example, for most Pacific island 
countries and territories the catchment populations are too small to supply the necessary number of samples to warrant the investment in national confirmatory testing capacity, and therefore it is necessary to rely on the PPHSN-coordinated laboratory network to facilitate overseas testing.

Feedback from Pacific island countries and territories indicated that they appreciated the tailored tool and the one-to-one assistance provided to apply the tool. Pacific island countries and territories expressed their desire for future IHR (and other) assessment tools to be shorter and simpler, noting that they would be better received, more useful to individual nations and more likely to be completed in time. The IHR (2005) assessment tools could be simplefied by excluding questions not directly related to the core capacities of the IHR (2005) or stratifying questions into core and supporting questions so countries can prioritize the essential (and legally binding) IHR (2005) core capacity requirements.

Although mentioned in the IHR (2005) documentation, several Pacific island countries and territories' officers responsible for completing IHRMQ did not realize that they could report successful national fulfilment of core capacities if their nation drew on sources/services from neighbouring countries or from international preparedness, surveillance or response capacities for national purposes. To address this misunderstanding, and to address the issue of the IHRMQ's length and complexity, modification could be made to the response options or accompanying instruction documentation.

A key finding from our evaluation of the assistance provided was that contextualization of global tools was well received. The importance of WHO's regional and country offices for country liaison and provision of support to apply WHO-developed tools is of paramount importance.

Harmony between IHR (2005) and other global, regional, subregional and national health emergency capacity development frameworks is also critical. Where possible, objectives of various frameworks should be closely aligned and complementary. Similarly, where possible, assessment processes should be standardised to lessen the resource drain on already over-burdened ministries.

\section{CONCLUSION}

The IHR (2005) and the 2012 IHRMQ provide a valuable framework within which nations can assess current capacity and develop plans to address gaps. However, when considering very small population countries, the need for flexibility and adaptability should be considered. In our experience, WHO's (or other development agencies') assistance to interpret global monitoring tools is appreciated, aids understanding, and will likely facilitate higher quality, timely and complete reporting. There are calls from small nations to streamline planning and assessment processes to reduce the burden placed on limited national public health staff. This can, in part, be achieved by ensuring planning and assessment tools are clear, focused and succinct.

\section{Conflicts of interest}

None declared.

\section{Funding}

None.

\section{Acknowledgements}

We acknowledge the work and support of our colleagues from SPC (Yvan Souares, Pascal Frison and Christelle Lepers) and WHO (Chin-kei Lee, Ailan Li and Boris Pavlin). We also acknowledge our national counterparts for their active participation in this project.

\section{References:}

1. The International Health Regulations (2005). Geneva, World Health Organization, 2007 (http://www.who.int/ihr/ finalversion9Nov07.pdf, accessed 20 September 2012).

2. Information to States Parties regarding determination of fulfilment of IHR Core Capacity requirements for 2012 and potential extensions. Geneva, World Health Organization, 2012 (http://apps.who.int/iris/bitstream/10665/70820/1/WHO_HSE GCR_2012.1_eng.pdf, accessed 25 September 2012).

3. International Health Regulations Monitoring Questionnaire, 2012 edition. Geneva, World Health Organization, 2012.

4. Pacific Islands' Population tops 10 million. Fiji, Island Business Magazine, 2011. 
5. Data - Pacific island small states. Washington, DC, World Bank, 2012 (http://data.worldbank.org/region/pss, accessed 28 June 2012).

6. Pacific Public Health Surveillance Network. New Caledonia, Secretariat of the Pacific Communities, 2012 (http://www.spc.int/ phs/pphsn/, accessed 28 June 2012).

7. Kool JL et al. Pacific-wide simplified syndromic surveillance for early warning of outbreaks. Global Public Health, 2012, 7:670-681. doi:10.1080/17441692.2012.699536 pmid:22823595
8. Paterson BJ et al. Sustaining surveillance: evaluating syndromic surveillance in the Pacific. Global Public Health, 2012, 7:682-694. doi:10.1080/17441692.2012.699713 pmid:22817479

9. Asia Pacific Strategy for Emerging Diseases (2010). Manila, World Health Organization Regional Offices for the Western Pacific, 2011 (http://www.wpro.who.int/emerging_diseases/documents/ ASPED_2010/en/index.html, accessed 28 June 2012). 